\title{
Research-informed strategies to address educational challenges in a digitally networked world
}

\author{
Joke Voogt ${ }^{1,2} \cdot$ Gerald Knezek $^{3}$. \\ Natalie Pareja Roblin ${ }^{4,5}$
}

Published online: 3 September 2015

(C) The Author(s) 2015. This article is published with open access at Springerlink.com

\begin{abstract}
This special issue represents the scholarly work that emerged from the EDUsummIT 2013. EDUsummIT is a growing and active community of researchers, policy makers and practitioners that is committed to promote research-informed strategies to effectively integrate ICT in educational policy and practice. First the background and aim of EDUsummIT is presented, followed by an overview of the contributions to this special issue.
\end{abstract}

Keywords EDUsummIT · Research · Policy · Practice $\cdot$ Digitally networked world

\section{Introduction}

This special edition of Education and Information Technologies presents scholarly consensus distilled from the Third International Summit on Information and Communication Technologies (ICT) in Education (EDUsummIT 2013). This invitational gathering of 100 ICT researchers, practitioners and policy makers from more than 30 countries was held in Washington, D.C., Sept. 30 - October 2, 2013. The main goal of EDUsummIT 2013 was to define joint research-informed strategies at national,

Joke Voogt

j.m.voogt@uva.nl

Gerald Knezek

gknezek@gmail.com

Natalie Pareja Roblin

natalie.parejaroblin@ugent.be

1 University of Amsterdam, P.O. Box 15776, 1001NG Amsterdam, Netherlands

2 Windesheim University of Applied Sciences, Zwolle, Netherlands

3 University of North Texas, 3940 North Elm St. G150, Denton, TX, USA

4 University of Ghent, Henri Dunantlaan, 2, 9000 Ghent, Belgium

5 University of Pittsburgh, Pittsburgh, PA, USA 
regional and international levels to address successfully the challenges educational systems face in a digital and networked world. Thematic working groups (TWGs) debated reviewed literature, current issues and formulated recommendations for ICT in education under the theme "Research-informed Strategies to address Educational Challenges in a Digitally Networked World".

EDUsummIT 2013 resulted in an Action Agenda (http://www.curtin.edu.au/ edusummit/local/docs/EduSummIT_2013_Action_Agenda.pdf). TWG leaders remained in Washington D.C. for two additional days and discussed recommendations for actions with representatives of professional associations attending the U.S. National Technology Leadership Summit (NTLS 2013). EduSummIT 2013 participants later presented and discussed with professional audiences the Action Agenda at the American Educational Research Association Conference in 2014, the Society for Information Technology \& Teacher Education in 2014, the UNESCO Regional Conference on the "Quality of Education and Challenges in a Digitally Networked World" (Sofia, Bulgaria, October 2014), and many other venues. Refinements of Washington D.C. initial discussions among EDUsummIT participants themselves and with other professional association audiences, have been distilled into the eight papers presented in this special edition. A brief history of EDUsummIT and outcomes from previous meetings will be presented in the following section, followed by an overview of the content of each special edition paper.

\section{Background}

EDUsummIT is a global community of researchers, policy-makers and educators committed to promoting active dissemination and use of research findings to inform policies and practices that are concerned with the effective integration of ICT in education. EDUsummIT emerged from the publication of the International Handbook on Information Technology in Primary and Secondary Education (Voogt and Knezek 2008). Key persons involved in the international handbook realized that more than 40 years of research in ICT in education synthesized in the handbook, often had not found its way into educational policy and practice. To be able to develop a profound understanding of the realities of policy and practice and to jointly create the conditions to foster the integration of ICT into education, members of the research community, policy officials and practice innovators need to meet and talk to each other. Based on a shared understanding among researchers, policy makers and practitioners the primary goal of EDUsummIT thus has been to outline research-informed action steps to promote the integration of information and communication technology in education.

In 2009, 70 leading researchers, policy makers and educators, spanning six continents, gathered in The Hague (The Netherlands) for the first EDUsummIT. The 2-day gathering resulted in a Call to Action on the future of ICT in education (http://www. curtin.edu.au/edusummit/edusummit-archive/call-to-action-2009.cfm) as well as a scholarly contribution to support the Call (Voogt et al. 2013a). Following up on the results of the EDUSUmmIT 2009, a second meeting was organized in 2011 at the UNESCO Headquarters in Paris. This summit gathered over 120 participants from across the world with the goal of establishing a clear view of the role of ICT in the $21^{\text {st }}$ Century. EDUsummIT 2011 resulted in a report (http://www.curtin.edu.au/edusummit/ local/docs/EDUummITReportSpreadFrmt2A4.pdf) and scholarly output in the form of 
a special issue of the Journal of Computer Assisted Learning (volume 29/issue 5). The third EDUsummIT was held in Washington D.C. and resulted in an Action Agenda. The scholarly output of EDUsummIT 2013 will be presented in this special issue of Education and Information Technologies. EDUsummIT 2015 will take place in September 2015 in Bangkok, Thailand, and is organized in close cooperation with UNESCO Bangkok. The theme of the 2015 gathering is "Technology Advanced Quality Learning for All."

Since the first meeting in 2009, EDUsummIT has established a growing network of stakeholders committed to strengthen the dissemination and impact of research evidence on future policies and practices of governments, educators and researchers. EDUSummIT is organized with the support of prominent international and national organizations actively promoting the use of ICT in education: the Society for Information Technology and Teacher Education (SITE), the International Society for Technology in Education (ISTE), Kennisnet (The Netherlands), the International Federation for Information Processing (IFIP - working group named Research on Education and Applications of Information Technology), the Association of Teacher Educators (ATE), and the UNESCO's Teacher Development and Higher Education Division.

\section{Themes}

Themes discussed during the EDUsummITs conceptualize issues related to the integration of ICT in education based on the inter relationships between macro, meso and micro perspectives. EDUsummIT themes emerge from profound discussions among the organizers of EDUsummIT, and are infused with input from the international organizations that support the activities. TWG leaders prepare a pre-summit paper, which is the basis for the discussions in the thematic working groups. In interactive working group sessions participants engage in an active dialogue around the selected themes. Within each thematic working group, conversations focus on the identification of current needs and concrete recommendations for action that could contribute to address the needs effectively. Postsummit papers summarize the main findings and recommendations of each thematic working group (see http://www.curtin.edu.au/edusummit/ for pre- and post summit papers). EDUsummIT 2013 (Washington D.C.) continued to work on some of the themes of EDUsummIT 2011 (Paris), viz. education systems, mobile learning, assessment, professional development, digital equity and research. New insights related to these themes due to global and technological developments were discussed. Two completely new themes emerged for EDUsummIT 2013: computational thinking as an important $21^{\text {st }}$ century skill, dominating the discussion on computer and information science in school curriculaand global digital citizenship as a complex concept and challenge related to the (proper) use of web 2.0 technologies.

\section{Overview of papers in this special issue}

The EDUsummIT 2009 call to Action acknowledged that there was a need "To better understand student technology experiences in informal learning environments, in order to inform learning in formal settings" (EDUsummIT 2009). Mobile technologies 
provide opportunities for a natural relationship between formal and informal learning and was further advanced in EDUsummIT 2011. In EDUsummIT 2013 this theme developed into mobile learning. Khaddage, Christensen, Lai, Knezek, Norris and Soloway discuss mobile learning as a relatively new but increasingly prominent field in ICT in education. There can be no doubt that access to mobile technologies is rapidly growing and changing the ways in which people learn and construct knowledge. Together with the many opportunities, this also presents several challenges to educational institutions with respect to the implementation of mobile learning. The authors discuss these challenges from a pedagogical, technological, policy and research perspective. Building on existing literature, a framework is proposed to overcome these challenges and guide the planning and implementation of mobile learning experiences across formal and informal education.

Mobile learning is one of many examples about how technologies can be used to support innovative practices in schools (Kozma 2003). Yet, the extent to which the use of technology has effectively led to fundamental changes in the educational system as such still remains an open question. Erstad, Eickelmann and Eichhorn address this problem, and focus on the role of teachers as key agents of change. Three contemporary approaches to new forms of schooling are discussed in relation to whether and how they challenge and change teacher roles.

The importance of professional development to ensure that teachers are well prepared to integrate technology in ways that facilitate both novel and enhanced learning opportunities is also addressed by Albion, Tondeur, Forkosh-Baruch and Peeraer. A conceptual model of teacher professional development for technology-enabled learning is proposed, and four successful cases are described to illustrate the elements in the model and the interactions among them. The authors stress the need for more evidencebased decision-making, and advocate design-research as an ideal approach to reduce the gap between ICT in education research and practice.

It is generally accepted that technology integration is often not successful when there is a gap between the intended outcomes of a technology-enhanced environment for learning and assessment practices at the national and school level. For this reason assessment has always been an important theme of EDUsummIT. Two papers in the current special issue address recent developments in technology-enhanced assessments, and the opportunities and challenges that these present. The first paper by Webb and Gibson discusses the potential of technology-based assessments for assessing higher levels of knowledge and performance, with a specific focus on collaborative problem solving. The authors argue that a technologyenabled collaborative learning environment can be a rich context for assessing higher order skills, as long as 1) the purpose and design of the assessment is clear about its targets, 2) the assessment tasks are constructed to include technology as part of the collaborative problem solving task, and 3) the assessment provides timely useful feedback to teachers and students. In a second paper, Gibson and Webb extend this analysis by discussing major data challenges concerning the amount, type and velocity of information potentially available in technology-enhanced assessments. Three cases are presented to illustrate how the identified challenges can be addressed in the development of educational assessments.

The competencies needed for living, learning and working in the $21^{\text {st }}$ century have always been an important part of the EDUsummIT discussions. While in previous EDUsummITs $21^{\text {st }}$ Century competencies were discussed in general (Voogt et al. 2013b), EDUsummIT 2013 focused on two $21^{\text {st }}$ century competencies in particular, viz. 
computational thinking and global digital citizenship. In these contributions technology is positioned as an educational goal, and not only as a tool for teaching and learning.

The contribution of Voogt, Fisser, Good, Mishra and Yadav specifically addresses computational thinking. Since Wing's (2006) influential article on computational thinking, the discussion about what computational thinking entails, how it can be developed and what its place is in the curriculum of elementary and secondary education has been discussed worldwide. The authors situate the discussion in history, elaborate on core and peripheral attributes of computational thinking, and present examples of how it can be integrated in the curriculum.

Searson, Hancock, Soheil and Shepherd focus on digital citizenship within global contexts. The authors present a critical account of the meaning of digital citizenship and of the factors that could either empower or limit it. The models of two well-known and respected organizations - the International Society for Technology in Education (ISTE) and iKeepSafe - are presented as examples of how to conceptualize the development of digital citizenship in educational settings. Based on these examples and on the discussions held at EDUsummIT 2013, the authors formulate several recommendations and concrete action steps to promote digital citizenship skills and competencies in and beyond school settings.

The final paper in this special issue discusses digital equity. The contribution of Resta and Laferrière to the current special issue focuses on this particular topic and discusses the intricate relationships between digital equity and intercultural education. The authors address current challenges and opportunities regarding digital equity, as well the increasingly important role technology plays in helping to foster intercultural understanding and education.

Collectively, these papers address a wide range of important topics and issues in the field of ICT in education. We trust that the reader will find the papers in this special edition enlightening in content, and focused on research-informed action steps designed to improve the integration of information and communication technologies into education.

Open Access This article is distributed under the terms of the Creative Commons Attribution 4.0 International License (http://creativecommons.org/licenses/by/4.0/), which permits unrestricted use, distribution, and reproduction in any medium, provided you give appropriate credit to the original author(s) and the source, provide a link to the Creative Commons license, and indicate if changes were made.

\section{References}

EDUsummIT (2009). Call to Action. The Hague: EDUsummIT 2009. Retrieved http://www.curtin.edu.au/ edusummit/edusummit-archive/call-to-action-2009.cfm.

Kozma, R. B. (Ed.). (2003). Technology, innovation and educational change. A global perspective. Eugene: ISTE Publ.

Voogt, J., \& Knezek, G. (Eds.). (2008). International handbook of information technology in primary and secondary education. New York: Springer.

Voogt, J., Knezek, G., Cox, M., Knezek, D., \& Ten Brummelhuis, A. (2013a). Under which conditions does ICT have a positive effect on teaching and learning? A call to action. Journal of Computer Assisted Learning, 29(1), 4-14.

Voogt, J., Erstad, O., Dede, C., \& Mishra, P. (2013b). Challenges to learning and schooling in the digital networked world of the 21st century. Journal of Computer Assisted Learning, 29(5), 403-413.

Wing, J. M. (2006). Computational thinking. Communications of the ACM, 49(3), 33-35. doi:10.1145/ 1118178.1118215 . 